\title{
Characteristics of Strategic Subcontracting Relations of Industrial SMEs
}

\author{
Maria Vasilska \\ Institute of Entrepreneurship, University of \\ National and World Economy, Sofia, Bulgaria
}

\begin{abstract}
The paper explores and analyses the activities of industrial small and medium-sized enterprises (SMEs), working as subcontractors, that have built sustainable relationships with at least one of their clients. It focuses on the importance of such dealings for SMEs that enables them to overcome their inherent weaknesses, to enhance competitiveness and to realize promising development. For that reason, subcontractors usually seek to build strategic partnerships with contractors. The paper reveals the main characteristics of the buyer-supplier relations that could be defined as strategic to the subcontracting SMEs, such as: to be sustainable over time, to provide access to key resources and innovations, to lead to acquisition of new competitive advantages and growth, etc. In addition, the paper presents some key traits of the relations that mark the existence of a mutual strategic partnership between subcontractors and their clients. The data and methods used in the paper include a study of literature sources, an investigation of available research findings, results of the author's individual research and expert observations, as well as data from a collective research project. ${ }^{1}$
\end{abstract}

Keywords: small and medium-sized enterprises, entrepreneurship, strategic subcontracting, competitive advantages, contractors, subcontractors

\section{Introduction}

The dynamically changing consumer demands and the highly intensified competition in most markets today lead to changes in the relations between industrial enterprises, to increasing specialisation and division of labour at inter-company, national and international level, reflecting in the growing use of subcontracting as a method of production organisation.

\footnotetext{
${ }^{1}$ Acknowledgement: This paper was supported by a grant from the National Science Fund of the Bulgarian Ministry of Education and Science, Contract No ДH05/15 of 15.12.2016: Determinants and models of the competitive performance of small and medium-sized enterprises in international business environment.
} 
There are numerous studies and publications discussing on: the reasons that urge large companies to use subcontractors; the activities that they could assign to external manufacturers and those that they should keep inside; the benefits of the reasonable and well-organised use of suppliers; the procedures for selection of subcontractors and the ways to evaluate their performance; the decision to turn them into strategic partners, etc. It can be summarised that the available literature and research focuse mainly on the reasons, benefits and mechanisms by which large companies use subcontractors. The decisions, strategies and activities of subcontractors (often micro, small or medium in size) are rarely subject of research and publication. Even less - when subcontracting can be considered as a strategic lever for business development.

For these reasons, the paper focuses on the buyer-supplier relations through investigation of the subcontractors' point of view. It presents the most important indicators for determining such relations as strategic for the subcontractor companies but also - some key characteristics that mark the existence of a mutual strategic partnership. The data and methods used in the paper include a study of literature sources, an investigation of available research findings, results of the author's individual research and expert observations, as well as data from a collective research project.

\section{Theoretical basis}

\section{SMEs' strategic partnerships}

SMEs are one of the engines of the economic development of most countries. Moreover, they solve tasks that are important to the society, such as creating employment or serving small market niches that embrace specific consumer needs.

The group of SMEs is rather heterogeneous and it is characterised by different business models. There is not a big discussion in the specialised literature on the statement that the main alternative business models, implemented by SMEs, are the ones of small manufacturers and subcontractors (Cagliano\&Spina, 2002). The first model is applied by companies manufacturing small production runs of products designed for a particular group of clients. SMEs that cannot or do not want to be independent small producers choose the second business model, finding their market in the face of large companies of which they become subcontractors.

When applied wisely, both business models can lead to market success, competitive growth and promising development. Nevertheless, whatever SMEs have chosen, the practice shows that they can hardly progress so alone. That is why entrepreneurs and SMEs' managers usually strive for entering and developing partnerships with other, often larger, companies. Through strategic collaboration SMEs are able to: overcome their inherent weaknesses (isolation, resource scarcity), gain greater results from their core strengths, share risks with partners, quickly respond to changes in the environment and undertake considerable strategic initiatives. 
Along with the benefits of their involvement in strategic partnerships, SMEs' entrepreneurs and managers face a number of difficulties and problems related to finding a suitable partner, division of rights in relation to joint inventions and other objects of intellectual property, determination of the contribution of each partner to the joint activities, as well as distribution of their benefits. Major obstacles to maintaining sustainable relationships are the large difference in the size of the enterprises, the risk of losing independence of one of the partners and others. However, when the partnership is strategically oriented, the size should not matter: the dependence is mutual and it is not used by one of the partners to the detriment of the other. Therefore, when an entrepreneur purposefully looks for a suitable partner with whom to build strategic cooperation, the best first step is to review his/her already established personal and business relationships. And then, step by step, the strategic partnership is to be developed. Its components and stages may be different depending on the characteristics of the partners and the goals set. One possible model of building a strategic partnership is presented in Figure 1.

\section{Figure 1. Components and stages of building a strategic partnership}

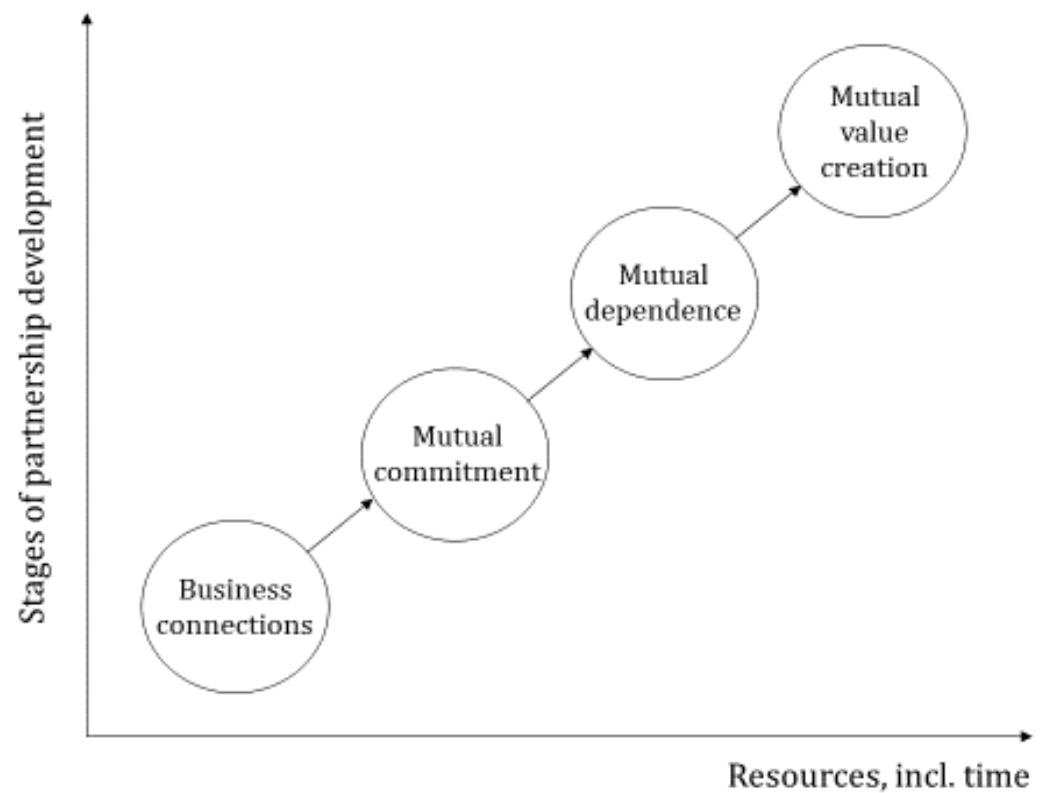


Source: Adapted from: Holm, D. B., K. Eriksson, J. Johanson (1999). Creating value through mutual commitment to business network relationships. Strategic Management Journal, No 20, 1999, p. 470.

\section{Subcontracting relations of industrial SMEs}

Subcontracting activities can be divided into industrial and trade ones. In industrial subcontracting products are used as components in the contractor's manufacturing process, while trade subcontracting means production intended to be wholesaled by another company (Yurukova, 2009, p. 144). There are not many variations in the views about the essence of the industrial subcontracting in literature. A detailed definition was given by Thorburn and Takashima in 1992, who described it as "the provision, by one firm to another, of relatively specialised inputs, which are then incorporated into the final product of the buying firm. These inputs are distinguished from inputs of a standard kind such as raw materials or electric power, which can be purchased on the open market... It has the implication of a continuing (though not necessarily continuous) relation between the buying firm ... and the subcontractor which may be backed by legal contract, or trust, or both. Often, though not always, the supplying firm may be small in relation to the principal." (Cited from Curran\&Blackburn, 1994, p. 30). Usually the aim of such dealings is a synergetic effect for both enterprises to be achieved and the collaboration may have a strategic character for one or both sides.

Stimuli and motives for SMEs to become subcontractors could be various. However, some important advantages of subcontracting activity might be: stable production orders and sales without considerable marketing costs and risks (the juridical, financial and other responsibilities for the completion and sale of the end output is taken by the contractor); opportunities for borrowing technical and managerial know-how from the client; getting consultancy by the large company in different areas - manufacture, HRM, organisation; gaining experience for working in international environment; opportunities for creation and adoption of product and process innovations, which have an assured market; specialisation in one activity and, as a result - achieving economy of scale; increasing the image when working for wellknown clients (Yurukova, 2007, pp. 465-466).

Some risks and weaknesses of subcontracting activity for SMEs can be related to: small size of the profit; irregular orders (lack of long-term contracts); loss of touch with the wide market; loss of independence, flexibility, innovativeness, valuable know-how, etc. (Yurukova, 2009, p. 146). SMEs subcontractors could also face some challenges connected with difficulties to deal with the globalisation's peculiarities; lack of necessary resources or managerial capabilities that hinder them to take on more voluminous and complex tasks (Harizanova\&Tsvetkova, 2013, p. 124-125); complicated procedures of negotiation; too high requirements for quality control, production schedules and personnel qualification; etc. 
With time, through using advantages and avoiding disadvantages of the subcontracting activity, SMEs could develop in two main directions:

First, it is possible for them to turn to more perspective activities. From "fire brigade" used for compensation of lack of production capacity of the large enterprises and some other "emergences", they could transform into specialised subcontractors, which possess a technology that the client companies need.

Second, with the help of the knowledge, experience and resources gained, they could invest in developing their own products and in their market realisation (to switch to the first business model). In most cases the manufacture of products with its own brand is tied to larger profits and growth opportunities, but there are many risks that must be stipulated and reduced.

\section{Subcontracting as a buyer-supplier strategic partnership}

The following exposition synthesises the views of many authors regarding the nowadays manner of interaction between subcontractors and their clients, that replaced the traditional model of relationships and leads to synergetic and lasting effects for both parties.

The interest in the role of the supplying enterprises increased as a result of the decentralisation processes of large companies started in the 1970s and widely discussed in the specialised literature (Villa\&Panizzolo, 1996; Cagliano\&Spina, 2002; Cousins et al., 2008; etc.). In the subsequent decade, however, subcontracting relationships have been usually seen as unequal interactions based on the predominance of power of the buying companies, influencing the decisions and strategies of the suppliers. The subcontractors have not had many opportunities to differentiate their offers and have usually been chosen by manufacturers due to their geographical proximity and/or low price of the services. Such a position in the supply chain has not always been attractive to the small companies and therefore has been perceived as inevitable, but the only acceptable solution for SMEs that did not possess the necessary resources or abilities to be independent producers.

After the 1980s, the role of subcontractors gradually began to change. Products and markets developed by large manufacturers became more complex and the companies started to face difficulties to coordinate the use of a variety of external resources and competencies supplied by multiple subcontractors. For this reason, they increasingly began to rely on a limited number of privileged subcontractors (delivering more complete and/or complex products, as well as a larger volume of work), interrupting their orders to other suppliers (Harizanova\&Tsvetkova, 2013, p. 130; Vasilska, 2020, p. 741). Subcontracting networks became pyramid structures in which the contractors relied on a small number of strategic suppliers, which in their turn assigned tasks to a significant number of lower-tier subcontractors. Examples of this evolution of subcontracting relationships can be found firstly in the automotive industry, as well as in some other machine-building sectors. 
In this light, the importance of subcontractors is much greater than that of ordinary suppliers of production capacity. Those of them who have managed to become major suppliers to large-scale manufacturers could generate high added value in the activities they perform. This is due to the greater opportunities for differentiation based on specialised technology, flexibility or low cost.

With the presence of such prerequisites, an industrial subcontracting partnership can be built. This concept is based on the modern approach to organising and managing the relationship between large manufacturers and their suppliers, characterised by tight specialisation and technological expertise of subcontractors and leading to sustainable, fair and, to some extent, balanced relationships.

In addition to the above, the main features and advantages of the current subcontracting model can be pointed out:

Growing demand for reliable subcontractors with which large manufacturers could establish continuous and profitable partnerships, supported by long-term contracts; Involvement of subcontractors still in the phase of R\&D;

Increased integration and complexity of the products produced by the subcontractors;

Parts and products manufactured by subcontractors are supplemented with accompanying services, such as various R\&D, design, information, logistics and other services (Villa\&Panizzolo, 1996, p. 39);

Growing exchange of information and know-how between buyers and suppliers;

Acceleration of the innovation processes and taking more and more of them by subcontractors;

Increased flexibility of the production processes;

Cost reduction - a common task of contractors and subcontractors;

Reduction of delivery time ("just in time" production);

Strategic commitment of the goals, production plans and management philosophies of both companies;

Mutual dependency caused by the complexity of the relationships and the high investments needed (Gubik, 2005, p. 35).

In conclusion it can be pointed out that nowadays the industrial production, characterised by the increasing competition in terms of conquering new markets, product quality and cost reduction, often leads to the transformation of non-binding subcontracting relationships between established producers and their subcontractors into strategic ones. 


\section{Methodology and data sources}

Partnerships between enterprises of different sizes, incl. subcontracting ones, should be defined as strategic, based on an investigation of all parties involved. However, the research available in the literature is rarely voluminous and comprehensive enough and targets mainly large enterprises that have chosen to partner with smaller ones for various reasons. In addition, different business relationships may be of strategic importance to only one of the parties involved. It is really interesting, the point of view of the "weaker" in such relationships SMEs to be examined.

Part of the results of two empirical investigations (one - individual, and the other collective) is presented in the current paper. In both of them the author aimed to identify relationships that, due to the presence of certain characteristics, can be defined as strategic for subcontractors, and to indirectly determine whether they are the same for the contractors.

The author's individual research investigated 60 Bulgarian enterprises (selected after a preliminary pilot survey) meeting the following criteria:

to be micro, small or medium in size;

to be industrial ones;

to work predominantly as subcontractors;

to have at least one contractor that they consider as a major business partner.

The survey was aimed at identifying the most prevalent characteristics of the relationships between SMEs and their major partners that, accordingly, could be determined as the main features of subcontracting relations that are of strategic importance to the suppliers. The importance of the relations for the buying companies was indirectly assessed by the opinion of their subcontractors.

The author also uses data obtained from a representative survey of 500 Bulgarian SMEs developing different kinds of international activities. The survey was part of a fundamental scientific research project titled "Determinants and models of the competitive performance of small and medium-sized enterprises in international business environment" (2016-2021), funded by the National Science Fund of the Bulgarian Ministry of Education and Science, implemented by a research team with the participation of the author of this paper. Many of the investigated SMEs work as subcontractors for foreign companies but for 35 of them this is a main activity. All these 35 respondents answered that the partnership with the foreign contractors (listed among many other possible business partners) is of strategic importance for the development of their businesses. The main issues that the author verified within this investigation were whether there are competitive advantages that are strengthened or newly acquired by SMEs as a result of the business partnership with their main contractors, as well as whether there are some other benefits for them. 


\section{Summarised results of the empirical verification}

As a result of the conducted empirical investigations (described above), the most important criteria for the perception of a contractor as a strategic partner, which had a decisive influence on the development of the studied Bulgarian SMEs subcontractors, emerged. They are:

long duration of the business relations - this turns out to be the most important indicator for strategic orientation, because most of the surveyed companies define as their main business partner the contractor for which they work the longest;

large-scale orders - the work assigned by the main contractor forms a significant share of the turnover of the surveyed enterprises;

delivery of a (part of) product that is important for the contractor - many of the studied subcontractors produce complex or fully completed products that allow them to develop their potential, to achieve a good profit, and, at the same time - to satisfy the contractor's requirements;

implementation of changes, reorganisations and innovations for the needs of the contractor's production, which are also valuable for other aspects of the enterprises' activities, as well as for their future development;

acquisition of new or strengthening existing competitive advantages - big part of the research objects has gained specialised technological expertise, has increased the speed and/or quality of the provided service or has reduced its costs;

access to key resources - technologies, equipment, production materials, information, consultancy, etc.;

growth and development - more than two thirds of the enterprises have hired new employees and have increased their turnover as a result of the increased and complicated orders of the contractors. Continuous financial inflows have led to investments not only in the expansion of cooperation, but also in development in other areas;

size and prestige of the contractor - huge part of the contractors are large enterprises with established reputation or production units of multinational corporations;

building an image and finding other strategic partners - the acquired status of a reliable supplier of a well-known manufacturer in many cases leads to attracting new large customers (mainly - foreign ones).

Another important conclusion can also be drawn out of the empirical research: a valuable subcontracting partnership is built when the relationship is of strategic importance for both parties involved. Based on the additional information obtained from a large part of the surveyed enterprises, the main characteristics of such a partnership can be deduced: 
mutual benefit based on specialisation and cost reduction - both parties specialise within their areas of competence, which leads to economies of scale. At the same time, they reduce or eliminate some costs as a result of the established subcontracting relationships;

sustainability of relations - both companies benefit from the long-term cooperation, which allows them to plan activities, to cut efforts and costs for finding new counterparties;

precise fulfilment of obligations and certainty in the relations - the constant correct execution of the formal agreements leads to achieving certainty in the relations and turning the parties into reliable for each other partners;

fair distribution of the risks and the benefits of the collaboration depending on the contribution of each party;

presence of an innovative element in the relationship - the sustainable subcontracting partnerships are based on the availability of specialised technological knowledge or equipment of subcontractors, not on benefiting from their cheaper services;

good interpersonal relationships, tolerance and coherence in doings - personal cooperation between entrepreneurs or employees, who are responsible for communication with the partner, leads to less problematic business relationships. Both sides are making compromises in order to keep and develop the cooperation;

mutual and comparable dependence, leading to difficult replacement of the partner the mutual mid or high-level dependence is important because neither party can easily end the relationship. This provides security for both companies, as well as opportunity for strategic planning of the business. The dependence should not be used by one of the parties to harm the interests of the other.

An important prerequisite for the development of sustainable subcontracting relations is the presence of relative comparability in the size and resources of the two enterprises. The empirical investigations give grounds the conclusion to be drawn that established strategic subcontracting partnerships predominantly have the medium-sized enterprises, and their growth is connected to the increasing orders of the key customers during the years of collaboration. The absence of a pronounced dominance of one of the sides in the relationship is a condition for building a mutual strategic partnership. Nevertheless, the empirical results show that balance is not a common feature of these relationships. The difference in the scale of the companies or in their degree of dependence leads to a predominance in the power of one of the parties. When this advantage is not used incorrectly, a strategic partnership can be built after all.

\section{Conclusions and recommendations}

Subcontracting is a widely used method of division of labour between industrial enterprises. The subcontractor usually offers something that the large manufacturer 
is not able to do easily and/or profitably by itself. Sometimes the latter is dependent on the specialised knowledge of the subcontractor. The buyer company, in turn, secures the subcontractor's market and brings other benefits, especially when it is considered by the smaller firm as a partner.

The set of criteria that would determine a contractor as a strategic partner should be unique to each company. It could differ according to the subcontractor's industrial specialisation, size, innovation focus, strategy, goals (growth, diversification, internationalisation), as well as depending on the characteristics of the contractor and the subject of their relationship. Nevertheless, based on empirical investigations conducted among Bulgarian SMEs subcontractors, the current paper presents the most important criteria for the perception of a contractor as a strategic partner, as well as some key characteristics of the mutual subcontracting partnership, that may be applicable in other national contexts.

The empirical results presented in the paper and the analyses made provide a basis for making recommendations to entrepreneurs and managers of SMEs that work as subcontractors. Basically, in order strategic to the supplying companies partnerships to be built, they must wish it and pursue it through behaving proactively. To enter the subcontracting networks of well-known manufacturers or to turn accidental relations into long-term and even strategic ones, it is necessary for the subcontractors to have specific competitive advantages or to be ready to acquire them in the short term. They should develop themselves purposefully in order to become preferred, reliable and hardly replaceable partners of reputable manufacturers. Moreover, they should strive for building relations that are of a strategic importance for both parties because the mutual subcontracting partnerships are more beneficial and stable. Building such relationships requires desire, time, trust, tolerance, precise fulfilment of obligations and coherence in plans and activities.

\section{References}

[1] Cagliano, R., G. Spina (2002). A comparison of practice-performance models between small manufacturers and subcontractors. International Journal of Operations \& Production Management, Vol. 22, No 12, 2002, pp. 1367-1388.

[2] Cousins, P., R. Lamming, B. Lawson (2008). Strategic Supply Management. Principles, Theories and Practice. UK: Pearson Education Ltd.

[3] Curran, J., R. Blackburn (1994). Small Firms and Local Economic Networks The Death of the Local Economy?. London: Paul Chapman Publishing Ltd.

[4] Gubik, A. (2005). New opportunities for SMEs founded by cooperation. European Integration Studies, Miskolc, Vol. 4, Number 1, 2005, pp. 25-36. Available online: www.unimiskolc.hu/uni/res/kozlemenyek/2005/pdf/gubik.doc 
[5] Harizanova, M., D. Tzvetkova (2013). Management of outsourcing and subcontracting. Sofia: UNWE Publishing complex (in Bulgarian).

[6] Holm, D. B., K. Eriksson, J. Johanson (1999). Creating value through mutual commitment to business network relationships. Strategic Management Journal, No 20, 1999, pp. 467-486.

[7] Vasilska, M. (2020). International Subcontracting - from Traditional towards Strategic Interfirm Relationships. Proceedings of scientific works from the 21st International Scientific Conference "International Relations 2020: current issues of world economy and politics", 3-4 December 2020, Bratislava, Slovakia. Bratislava: Publishing Ekonóm, pp. 737-743. Available online: https://fmv.euba.sk/www_write/files/veda-vyskum/konferenciasmolenice/2020/zborn\%C3\%ADk_19._1._20212.pdf

[8] Villa, F., R. Panizzolo (1996). Buyer-subcontractor relationships in the Italian clothing industry. An interpretive framework. In: International Journal of Operations \& Production Management, Vol. 16, No 7, 1996, pp. 38-61.

[9] Yurukova, M. (2007). Bulgarian SMEs Operating in International Subcontracting Networks: The Impact of the EU Accession Process. Proceedings of the international conference "Entrepreneurship in United Europe - Challenges and Opportunities", 13-17 September 2006, Sunny Beach, Bulgaria. Sofia: BAMDE, pp. 461-474.

[10] Yurukova, M. (2009). Challenges and Opportunities for the Bulgarian Industrial SMEs Operating as Subcontractors. Proceedings of the international conference "The European Entrepreneurship in Globalising Economy Challenges and Opportunities", 9-12 September 2008, Varna, Bulgaria. Sofia: BAMDE, pp. 141-155. 